\title{
Kampanye pemilihan presiden tahun 2019 dalam media cetak surat kabar Jawa Pos
}

\author{
Indra Marlina, ${ }^{1, a^{*}}$ Triwahyuningsih ${ }^{2, b}$ \\ a,b Program Studi PPKn, Universitas Ahmad Dahlan, Yogyakarta \\ ${ }^{1}$ indra1500009041@webmail.uad.ac.id, ${ }^{2}$ triwahyuningsih@ppkn.uad.ac.id \\ * korespondensi penulis
}

\begin{abstract}
ABSTRAK
Indonesia merupakan salah satu negara yang menganut paham demokrasi yang mendasari konsep partisipasi dalam pemilihan umum. Kampanye yang bertujuan untuk menarik simpatisan para khalayak umum melalui media kampanye. Pada realitanya dalam pelaksanaan kampanye terdapat penyimpangan seperti adanya kampanye hitam serta adanya janji yang berlebihan yang ditawarkan oleh calon kandidat. Penelitian ini bertujuan untuk menganalisis isi dan tujuan dari suatu kampanye, khususnya kampanye pemilihan presiden tahun 2019 yang terdapat dalam media cetak surat kabar harian Jawa Pos. Jenis penelitian menggunakan penelitian kualitatif, metode penelitian menggunakan analisis isi. Objek penelitian ini adalah semua isi kampanye calon presiden dan wakil presiden 2019 yang dimuat dalam media surat kabar Jawa Pos. Teknik pengumpulan data menggunakan analisis isi tentang berita Jawa Pos 1 Maret - 13 April 2019 dengan data pustaka dan dokumentasi, kemudian kategorisasi berita disesuaikan dengan indikator lalu disimpulkan. Hasil penelitian menunjukkan bahwa adanya janji politik kepada masyarakat yang bertujuan agar masyarakat mengetahui hal yang nantinya akan diperjuangkan calon kandidat. Program kerja yang direncanakan oleh calon kandidat dan timnya berupa visi dan program kerja (menyediakan lapangan pekerjaan) dapat memberikan kesejahteraan, mengurangi penganggur dan kemiskinan. Imbauan politik mengajak masyarakat untuk ikut serta menggunakan hak pilih dan ikut berperan aktif dalam pelaksanaan pemilu. Adanya saling sindir antar kandidat dalam kampanye.
\end{abstract}

Kata kunci: kampanye, pemilihan presiden, media cetak, surat kabar

\begin{abstract}
Indonesia is one country that adheres to the concept of democracy that underlies the concept of participation in elections. The campaign aims to attract sympathizers to the general public through campaign media. In reality in the implementation of the campaign there are irregularities such as black campaigns and excessive promises offered by prospective candidates. This study aims to analyze the contents and objectives of a campaign, specifically the 2019 presidential election campaign contained in the print media of the Jawa Pos daily newspaper. This type of research uses qualitative research, research methods using content analysis. The object of this research is all the contents of the 2019 presidential and vice presidential candidates' campaigns published in the Java Pos newspaper media. Data collection techniques using content analysis about the Java Pos news March 1 to April 132019 with library data and documentation, then news categorization adjusted to the indicators and then concluded. The results showed that there were political promises to the public aimed at making people aware of what candidates would be fighting for. The work program planned by the candidate and his team in the form of a vision and work program (providing employment) can provide welfare, reduce unemployment and poverty. Political appeal invites the public to participate in exercising their right to vote and to take an active role in the conduct of elections. There is mutual teasing between candidates in the campaign.
\end{abstract}

Keywords: campaigns, presidential elections, print media, newspapers

Copyright (C2020 Universitas Ahmad Dahlan, All Right Reserved

\section{PENDAHULUAN}

Pemilu merupakan sarana pelaksanaan kedaulatan rakyat yang dilaksanakan secara langsung, umum, bebas dan rahasia berdasarkan Pancasila dan UUD 1945. Secara empiris demokrasi akan berkembang apabila mendapatkan dukungan langsung dari masyarakat yang membuka ruang untuk melaksanakan pemilu, sehingga terbentuknya proses demokrasi. Pemilihan umum merupakan perwujudan yang nyata yang dapat kita lihat sebagai pelaksanaan demokrasi yang diselenggarakan setiap lima tahun sekali. Indonesia merupakan salah satu negara yang menganut paham demokrasi sebagaimana dicantumkan dalam Pasal 1 ayat 2 UndangUndang Dasar 1945 yang berbunyi: "Kedaulatan berada di tangan rakyat dan dilaksanakan menurut UUD". Di negara-negara demokrasi pemikiran yang mendasari konsep partisipasi politik yaitu kedaulatan berada di tangan rakyat. Pemilihan umum pertama kali diselenggarakan pada tahun 1955 hingga yang terakhir pada tahun 2019 (Taniredja et al., 2010). Saat ini demokrasi tengah menghadapi problem serta tantangan seperti rendahnya kepercayaan masyarakat kepada 
pemimpin, sehingga menimbulkan anggapan bahwa pemilihan tidak begitu penting, bermula dari anggapan tersebut hingga akhirnya masyarakat melakukan tindakan golput atau tidak menggunakan hak pilihnya dalam pemilu. Berdasarkan Pilpres 2019 terdapat 79 orang atau 33 persen yang tidak menggunakan hak pilih dari total pemilih terdaftar 235 orang (Fabian, 2019).

Sosialisasi mengenai visi, misi dan program kerja sering dilakukan melalui kegiatan kampanye yang dilaksanakan oleh para pasangan calon maupun tim sukses. Kegiatan kampanye merupakan kegiatan yang diselenggarakan sebelum pemilu berlangsung yang dilakukan dengan spontan, tertib dan mendidik. Hal ini sosialisasi politik merupakan produk dari proses pendidikan atau sosialisasi politik masyarakat (Ferdian, 2010). Pada kenyataannya kegiatan kampanye belum dilakukan secara baik oleh kalangan masyarakat, seringkali masyarakat dengan sengaja melanggar peraturan yang sudah ditetapkan (Wahidin, 2008). Hal ini dibuktikan dengan kampanye yang dilakukan oleh calon wakil presiden Ma'ruf Amin melakukan kampanye dengan bersilaturahmi ke pondok pesantren Al- Iman, Bulus, Purworejo, Jawa Tengah (surat kabar Jawa Pos edisi Rabu 27 Maret 2019).

Kampanye hitam sering kali menyelimuti pelaksanaan pemilu, kampanye hitam merupakan senjata yang paling ampuh yang digunakan untuk menjatuhkan reputasi dari lawan politiknya. Kampanye yang dilakukan oleh para pasangan calon kandidat capres dan cawapres biasanya diberitakan melalui media cetak, elektronik dan media online. Tujuan penyelenggaraan kampanye dilakukan agar masyarakat dapat mengetahui visi, misi dan program kerja yang akan dilaksanakan oleh para pasangan calon (Wahidin, 2008). Hal ini berdasarkan data yang diperoleh dari CNN Indonesia bahwa kampanye hitam menimpa pasangan calon Jokowi dan Ma'ruf yang dilontarkan dari tim sukses pasangan calon Prabowo-Sandi "Tidak akan ada lagi suara azan, wanita berhijab serta dilegalkan LGBT". Bukan hanya pasangan calon Jokowi-Ma'ruf pasangan calon Prabowo-Sandi juga menerima kampanye hitam yang dilakukan oleh tim sukses pasangan Jokowi-Ma'ruf yang menyebarkan foto edita serangan PKS, yang berisi penyebaran foto perempuan PKS yang sedang mengampanyekan partainya plus pasangan calon Prabowo-Sandi. Poster tersebut dibawah perempuan di edit kemudian diganti dengan tulisan \#2019tambahistri (surat kabar Jawa Pos edisi Kamis, 28 Maret 2019).
Media sosial tidak hanya digunakan untuk menyampaikan pemberitaan biasa tetapi juga, sebagai alat yang dapat digunakan oleh kandidat kampanye dan tim sukses untuk menyampaikan visi, misi dan program pasangan calon. Media sosial merupakan alat teknologi yang berkembang sangat cepat dimana seseorang dapat mengetahui informasi politik dalam beberapa detik saja, tidak dapat dimungkiri jika seorang politikus atau pemimpin politik tidak dapat dipisahkan dari media. Media sosial sendiri memiliki pengaruh yang kuat dalam pemilih (Fitri, 2018). Misalnya, setelah melihat atau membaca suatu isu atau informasi tentang calon kandidat baik informasi yang bersifat negatif maupun positif tanpa disadari komunikan akan terbawa emosional untuk melakukan atau tidak melakukan hal yang disampaikan oleh komunikator. Berdasarkan hasil pengujian hipotesis bahwa pada pemilihan presiden tahun 2014 dengan koefisien determinasi sebesar 0,496 atau 49,6\% banyaknya siswa terpengaruh oleh media (Retnawati et al., 2015).

Kampanye pemilu merupakan bagian dari pendidikan politik masyarakat dan dilaksanakan secara bertanggung jawab, hal ini berdasarkan data yang diperoleh dari surat kabar harian Jawa Pos edisi 16 Maret 2019 "Prabowo ajak relawan jadi saksi TPS". Pendidikan politik masyarakat dapat berupa mengajak atau memberikan pemahaman terkait pemilihan umum dan memberikan suara pada saat pemilihan. Arti bertanggung jawab dalam Pasal 267 tentang pemilu bahwasanya kampanye harus dilakukan menurut peraturan Undang-Undang yang telah ditemukan. Makna dari kata bertanggung jawab dapat diartikan bahwa setiap janji yang diucapkan pada saat kampanye dapat dipertanggung jawabkan oleh pihak yang membuat janji. Pada dasarnya tujuan dari kampanye yaitu terciptanya kepentingan bersama antara pihak yang mengajak dan pihak yang diajak. Realita yang sering kita jumpai hasil dari kampanye selalu saja menguntungkan pihak yang berkampanye. Misalnya saja, kampanye dengan menawarkan janji yang berlebihan seperti pada edisi Senin 1 April 2019 terkait kampanye Paslon nomor urut 02 apabila terpilih menjadi presiden akan menurunkan tarif listrik dalam kurun 100 hari kerja. Sementara setelah tujuan dari kampanye tercapai dan telah menduduki kursi jabatan seringkali kepentingan publik terabaikan. Untuk itu penting bagi kita sebagai pemilih agar dapat memahami pesan-pesan kampanye dalam media masa politik. Melihat dari masalah-masalah yang telah dijelaskan di atas penelitian ini bertujuan untuk menganalisis isi dan tujuan dari suatu kampanye, khususnya kampanye pemilihan 
presiden tahun 2019 yang terdapat dalam media cetak surat kabar Jawa Pos.

\section{METODE}

Penelitian ini menggunakan pendekatan kualitatif untuk mendeskripsikan gambaran karakteristik atau untuk menganalisis isi dari suatu pesan. Sedangkan metode penelitian menggunakan analisis isi. Dalam hal ini, penulis akan melakukan analisis terkait tulisan-tulisan yang terdapat pada surat kabar harian Jawa Pos. Objek dalam penelitian ini adalah semua isi kampanye calon presiden dan wakil presiden 2019 yang dimuat atau diberitakan oleh media kampanye surat kabar Jawa Pos.

Teknik pengumpulan data merupakan cara yang digunakan peneliti untuk mendapatkan data yang valid berdasarkan apa yang akan diteliti. Dalam penelitian ini peneliti menggunakan dua teknik dalam mengumpulkan data, yaitu: a) Data Pustaka, dalam penelitian ini Data kepustakaan digunakan oleh peneliti untuk mengumpulkan data-data relevan sesuai dengan masalah yang sedang diteliti, informasi dapat bersumber dari bahan-bahan yang bersifat relevan seperti, UU No 7 Tahun 2017 tentang pemilihan umum, jurnal dengan menggunakan studi kepustakaan. Tujuannya adalah untuk menarik kesimpulan sehingga dapat menjawab permasalahan yang diteliti; b) Dokumentasi yang dilakukan peneliti adalah observasi partisipasi, dimana peneliti ikut terjun langsung dalam kegiatan kemasyarakatan, dan kegiatan orang tua yang berkaitan dengan menanamkan nilai persatuan pada anak; c) Dokumentasi yang dilakukan oleh peneliti adalah dengan melakukan penelusuran dokumen data yang tersedia yang terdapat dalam surat kabar harian Jawa Pos. Data yang diperoleh disesuaikan dengan kategorisasi dan indikator yang telah ditetapkan sesuai dengan objek penelitian.

Dalam teknik analisis data penulis menggunakan analisis isi, yaitu digunakan untuk mengetahui gambaran karakteristik atau untuk menganalisis isi dari suatu pesan. Dalam hal ini peneliti mencari dokumen tentang kampanye presiden tahun 2019, kategori berita disesuaikan dengan indikator, isi berita dianalisis dan diambil kesimpulan.

Penelitian kualitatif adalah penelitian yang menghasilkan data deskriptif berupa kata tertulis atau lisan (Alwasilah, 2011). Penyajian data dalam penelitian ini mulai dari lokasi penelitian, objek penelitian yang berupa koran.

\section{HASIL DAN PEMBAHASAN}

Penelitian ini bertujuan untuk mengetahui berita-berita tentang kampanye presiden yang dilakukan oleh calon presiden dan calon wakil presiden 2019 yang dimuat dalam surat kabar harian Jawa Pos. Surat kabar harian Jawa Pos menyajikan informasi atau berita untuk masyarakat dan di dalam surat kabar harian Jawa Pos juga memberikan ruang khusus untuk beritaberita yang disampaikan seperti, informasi terkait olahraga, opini, ekonomi, internasional, iklan dan politika. Khususnya politika memberitakan isu tentang politik atau kampanye calon presiden dan calon wakil presiden 2019. Kampanye yang termuat dalam surat kabar harian Jawa Pos yang diterbitkan pada tanggal 1 Maret-13 April 2019. Berikut data kampanye yang dimuat dalam surat kabar harian Jawa Pos berdasarkan pada indikator penelitian sebagai berikut:

\section{Janji kampanye}

Janji kampanye adalah janji yang ditawarkan oleh calon kandidat dan tim kampanye dengan menjanjikan serta meyakinkan visi dan misi kepada masyarakat. Dengan janji tersebut dapat membawa dan memberikan perubahan yang lebih maju dan sejahtera. Janji kampanye yang terdapat dalam surat kabar harian Jawa Pos terdapat sembilan belas edisi, yaitu pada edisi 1 Maret 2019, edisi 3 Maret 2019, edisi 9 Maret 2019, edisi 25 Maret 2019, edisi 26 Maret 2019, edisi 27 Maret 2019, edisi 28 Maret 2019, edisi 29 Maret 2019, edisi 30 Maret 2019, edisi 1 April 2019, edisi 2 April 2019, edisi 4 April 2019, edisi 5 April 2019, edisi 6 April 2019, edisi 8 April 2019, edisi 10 April 2019, edisi 11 April 2019, edisi 12 April 2019.

\section{Program yang ditawarkan}

Program yang ditawarkan yaitu program yang disusun atau direncanakan oleh calon kandidat dan timnya. Program yang ditawarkan ini nantinya akan dilaksanakan apabila mereka terpilih menjadi presiden dan wakil presiden. Biasanya dalam program yang ditawarkan dapat berupa visi, misi dan program kerja (menyediakan lapangan pekerjaan). Program kerja disusun untuk menyelesaikan persoalan yang ada dan mampu membawah kesejahteraan serta dapat mengurangi pengangguran dan kemiskinan. Program yang ditawarkan selama masa kampanye yang terdapat dalam surat kabar harian Jawa Pos terdapat enam edisi, yaitu pada edisi 4 Maret 2019, edisi 19 Maret 2019, edisi 28 Maret 2019, edisi 2 April 2019, edisi 8 April 2019, edisi 13 April 2019. 


\section{Imbauan/sosialisasi politik}

Sosialisasi politik tentang pemilihan umum yang diberikan kepada individu, diharapkan akan memunculkan kesadaran politik individu untuk kemudian tidak hanya diam, tetapi dapat berperan dalam melaksanakan aktivitas berupa partisipasi politik warga negara dengan berbagai jenis tindakan (Subiakto \& Ida, 2012). Sosialisasi dan imbauan politik selama masa kampanye terdapat enam belas edisi, yaitu pada edisi 1 Maret 2019, edisi 4 Maret 2019, edisi 5 Maret 2019, edisi 6 Maret 2019, edisi 9 Maret 2019, edisi 12 Maret 2019, edisi 16 Maret 2019, edisi 22 Maret 2019, edisi 23 Maret 2019, edisi 27 Maret 2019, edisi 30 Maret 2019, edisi 31 Maret 2019, edisi 4 April 2019, edisi 9 April 2019, edisi 11 April 2019, edisi 13 April 2019.

\section{Sindiran dalam kampanye}

Di dalam menganalisis ada temuan selain yang disebutkan dalam indikator penelitian yakni kedua calon kandidat melontarkan kalimat sindiran. Pada saat masa kampanye terdapat adanya saling sindir antara kedua calon kandidat, yaitu terdapat pada edisi 9 Maret 2019, 16 Maret 2019, 25 Maret 2019, 31 Maret 2019, 8 April 2019.

\section{KESIMPULAN}

Berdasarkan hasil analisis dari berita diatas, dapat disimpulkan bahwa isi kampanye yang terkandung di dalam surat kabar harian Jawa Pos yang isinya memberitakan kampanye pemilihan presiden (Pilpres) selama masa kampanye diawali pada Edisi 1 Maret-13 April 2019, sebagai berikut: 1) Janji kampanye atau pesan politik kepada para pemilih yang termuat dalam surat kabar harian Jawa Pos sebanyak dua puluh edisi. Adapun dalam kampanye ini kedua kubu 01 dan 02 samasama menjelaskan janji politik kepada masyarakat. Tujuannya agar masyarakat dapat mengetahui hal yang nantinya akan diperjuangkan oleh keduanya apa bila mereka menerima mandat dari rakyat. Karena dengan begitu masyarakat akan menggunakan hak pilih nya dalam pemilu legislatif; 2) Program yang ditawarkan, adalah program yang disusun atau direncanakan oleh calon kandidat dan timnya. Selama kampanye legislatif, program yang ditawarkan dimuat dalam surat kabar harian Jawa Pos sebanyak enam edisi. Biasanya program yang ditawarkan dapat berupa visi dan program kerja (menyediakan lapangan pekerjaan). Pada intinya program yang ditawarkan mampu memberikan solusi dalam menyelesaikan persoalan yang ada di masyarakat serta mampu membawah kesejahteraan, dapat mengurangi pengangguran dan kemiskinan; 3) Imbauan atau sosialisasi kampanye yang termuat di dalam surat kabar harian Jawa Pos, selama masa kampanye legislatif tujuh belas edisi. Dalam kampanye tersebut sosialisasi politik atau imbauan politik mengajak masyarakat untuk ikut serta menggunakan hak pilih nya dan berperan aktif dalam pelaksanaan pemilu; 4) Adapun temuan lain dalam penelitian ini yaitu adanya saling sindir yang dilakukan oleh calon kandidat. Selama masa kampanye legislatif terdapat lima edisi sindiran antar kandidat.

\section{DAFTAR PUSTAKA}

Alwasilah, A. C. (2011). Pokoknya kualitatif: dasardasar merancang dan melakukan penelitian kualitatif. Dunia Pustaka Jaya.

Fabian, V. T. (2019). Hasil Pilpres 2019: 79 Pemilih Golput di TPS Jokowi. Tirto.ID. https//tirto.id\%3Ehasil-pilpres-2019

Ferdian, H. (2010, Oktober 27). Peran Partai Politik dalam Peningkatan Partisipasi Politik Masyarakat. Kompasiana.com. https://www.kompasiana.com/www.ilogo site.com/55003a2e8133111918fa7391/pera n-politik-dalam-kehidupan-sosialmasyarakat-penguatan-peran-partai-politikdalam-peningkatan-partisipasi-politikmasyarakat

Fitri, S. N. (2018). Pro Kontra Gerakan Tagar\#2019 Ganti Presiden sebagai Sarana Kampanye dalam Pemilu.

Retnawati, E., Suntoro, I., \& Nurmalisa, Y. (2015). Pengaruh Media Massa dan Sikap Politik terhadap Partisipasi Politik Siswa dalam Pemilu. Jurnal Kultur Demokrasi, 3(1). http://jurnal.fkip.unila.ac.id/index.php/JK $\mathrm{D} /$ article/view/7865

Subiakto, H., \& Ida, R. (2012). Komunikasi politik, media dan demokrasi. Prenada Media Group.

Taniredja, T., Muis, I., Sutrisno, S., Ridha, M., \& Suswanto, B. (2010). Pendidikan Kewarganegaraan Paradigma Terbaru Untuk Mahasiswa. Alfabeta.

Wahidin, S. (2008). Hukum Pemerintahan Daerah Mengawasi Pemilihan Umum Kepala Daerah. Pustaka Pelajar. 